Geopolítica(s) Revista de estudios sobre espacio y poder ISSN: 2172-3958

\title{
Carta a los gobernantes de América y Plan de realización del supremo sueño de Bolívar ${ }^{1}$
}

\author{
Augusto C. Sandino
}

Resumen. El nicaragüense Augusto C. Sandino fue uno de los líderes antiimperialistas más importante del siglo XX. Desde 1926 lidera una campaña contra la presencia estadounidense en su país hasta que en 1933 logra expulsar a los marines del mismo. Su pensamiento político, expuesto de forma fragmentaria en cientos de cartas, comunicados, discursos, partes de guerra, etc., tiene una matriz antiimperialista que hace pivotar sobre la necesidad de unidad de la "Nacionalidad Latinoamericana" para derrotar al enemigo del Norte. Este es el sentido principal de los dos documentos que se recogen aquí: urgir a los gobernantes latinoamericanos a rechazar la doctrina Monroe, organizarse políticamente, integrarse como comunidad política siguiendo la estela de Simón Bolívar y defender la soberanía e independencia latinoamericana.

Palabras clave: Nicaragua; Augusto C. Sandino; antiimperialismo; resistencia; pensamiento político.

\section{[en] Letter to the Rulers of America and Plan for the Realization of Bolivar's Supreme Dream}

\begin{abstract}
Nicaraguan Augusto C. Sandino was one of the most important anti-imperialist leaders of the 20th century. From 1926 he led a campaign against the American presence in his country until 1933, when he succeeded in expelling the Marines from it. His political thought, exposed in a fragmentary way in hundreds of letters, communiqués, speeches, war reports, etc., has an anti-imperialist matrix that revolves around the need for unity of the "Latin American Nationality" to defeat the Northern enemy. This is the main meaning of the two documents collected here: to urge Latin American rulers to reject the Monroe doctrine, to organize politically, to integrate as a political community in the wake of Simón Bolívar, and to defend Latin American sovereignty and independence.
\end{abstract}

Keywords: Nicaragua; Augusto C. Sandino; anti-imperialism; resistance; political thought.

1 [Nota de la redacción] Se incluyen en esta selección dos textos de Augusto César Sandino: el primero, "Carta a los gobernantes de América", escrito en El Chipotón, las Segovias, Nicaragua, C. A. el 4 de agosto de 1928, y el segundo, "Plan de realización del supremo sueño de Bolívar", escrito también en El Chipotón, las Segovias, Nicaragua, C. A. el 20 de marzo de 1929. Ambos están incluidos en la recopilación de escritos realizada por Sergio Ramírez: El pensamiento vivo (Managua: Editorial Nueva Nicaragua, 1984, vol. 1). El primero es el número 88, pp. 276-279, y el segundo es el número 111, pp. 341-355. Se ha respetado la integridad y estructura de los textos publicados en esta primera edición nicaragüense, que contiene una sustancial ampliación de documentos respecto a la primera edición de 1974 en San José de Costa Rica, así como fuentes más depuradas y un aparato de apoyo enriquecido. Se ha respetado la ortografía, estructura y énfasis de las transcripciones. 


\title{
[pt] Carta aos governantes da América e Plano para a realização do sonho
} supremo de Bolívar

\begin{abstract}
Resumo. O nicaraguense Augusto C. Sandino foi um dos líderes anti-imperialistas mais importantes do século XX. A partir de 1926 liderou uma campanha contra a presença norte-americana em seu país até que em 1933 conseguiu expulsar os fuzileiros navais. Seu pensamento político, exposto de forma fragmentada em centenas de cartas, comunicados, discursos, relatórios de guerra, etc., tem uma matriz anti-imperialista que gira em torno da necessidade de unidade da "Nacionalidade Latino-americana" para derrotar o inimigo do Norte. Este é o significado principal dos dois documentos aqui reunidos: instar os governantes latino-americanos a rejeitar a doutrina Monroe, a se organizarem politicamente, a se integrarem como uma comunidade política na esteira de Simón Bolívar e a defenderem a soberania e a independência latino-americana.
\end{abstract}

Palavras-chave: Nicarágua; Augusto C. Sandino; anti-imperialismo; resistência; pensamento político.

Sumario. 1 Carta a los gobernantes de América. 2. Plan de realización del supremo sueño de Bolívar.

Cómo citar: Sandino, A. C. (2021). Carta a los gobernantes de América y Plan de realización del supremo sueño de Bolívar. Geopolitica(s). Revista de estudios sobre espacio y poder, 12(2), 329-342. http://dx.doi.org/10.5209/geop.78605

\section{Carta a los gobernantes de América}

Señores presidentes:

Por ser los intereses de esos quince pueblos los que más afectados resultarían si se permite a los yankees hacer de Nicaragua una colonia del Tío Samuel, me tomo la facultad de dirigiros la presente, dictada no por hipócritas y falaces cortesías diplomáticas, sino con la ruda franqueza del soldado.

Los yankees, por un resto de pudor, quieren disfrazarse con el proyecto de construcción de un canal interoceánico a través del territorio nicaragüense, lo que daría por resultado el aislamiento entre las repúblicas indohispanas; los yankees, que no desperdician oportunidad, se aprovecharían del alejamiento de nuestros pueblos para hacer una realidad el sueño que en sus escuelas primarias inculcan a los niños, esto es: que cuando toda la América Latina haya pasado a ser colonia anglosajona, el cielo de su bandera tendrá una sola estrella.

Por quince meses el Ejército Defensor de la Soberanía Nacional de Nicaragua, ante la fría indiferencia de los gobiernos latinoamericanos, y entregado a sus propios recursos y esfuerzos, ha sabido, con honor y brillantez, enfrentarse a las terribles bestias rubias y a la caterva de traidores renegados nicaragüenses que apoyan al invasor en sus siniestros designios.

Durante este tiempo, señores presidentes, vosotros no habéis correspondido al cumplimiento de vuestro deber, porque como representantes que sois de pueblos libres y soberanos, estáis en la obligación de protestar diplomáticamente, o con las armas que el pueblo os ha confiado, si fuere preciso, ante los crímenes sin nombre que el gobierno de la Casa Blanca manda, con sangre fría, a consumar en nuestra desventurada Nicaragua, sin ningún derecho y sin tener más culpa nuestro país que no querer besar el látigo con que le azota, ni el puño del yankee que lo abofetea. 
¿Acaso piensan los gobiernos latinoamericanos que los yankees sólo quieren y se contentarían con la conquista de Nicaragua? ¿Acaso a estos gobiernos se les habrá olvidado que de veintiuna repúblicas americanas han perdido ya seis su soberanía? Panamá, Puerto Rico, Cuba, Haití, Santo Domingo y Nicaragua, son las seis desgraciadas repúblicas que perdieron su independencia y que han pasado a ser colonias del imperialismo yankee. Los gobiernos de esos seis pueblos no defienden los intereses colectivos de sus connacionales, porque ellos llegaron al poder, no por la voluntad popular, sino por imposición del imperialismo, y de aquí que quienes ascienden a la presidencia, apoyados por los magnates de Wall Street, defienden los intereses de los banqueros de Norte América. En esos seis desventurados pueblos hispanoamericanos, sólo habrá quedado el recuerdo de que fueron independientes, y la lejana esperanza de conquistar su libertad mediante el formidable esfuerzo de unos pocos de sus hijos, que luchan infatigablemente por sacar a su patria del oprobio en que los renegados la han hundido.

La colonización yankee avanza con rapidez sobre nuestros pueblos, sin encontrar a su paso murallas erizadas de bayonetas, y así cada uno de nuestros países, a quien llega su turno, es vencido con pocos esfuerzos por el conquistador, ya que, hasta hoy, cada uno se ha defendido por sí mismo. Si los gobiernos de las naciones que van a la cabeza de la América Latina estuvieran presididos por un Simón Bolívar, un Benito Juárez o un San Martín, otro sería nuestro destino; porque ellos sabrían que cuando la América Central estuviera dominada por los piratas rubios, seguirían en turno México, Colombia, Venezuela, etcétera.

¿Qué sería de México si los yankees lograran sus bastardos designios de colonizar Centro América? El heroico pueblo mexicano nada podría hacer, a pesar de su virilidad, porque estaría de antemano acogotado por la tenaza del Tío Samuel, y el apoyo que esperara recibir de las naciones hermanas no podría llegarle por impedirlo el Canal de Nicaragua y la Base Naval del Golfo de Fonseca; y quedaría sujeto a luchar con el imperio yankee, aislado de los otros pueblos de la América Latina y con sus propios recursos, tal como nos está sucediendo a nosotros ahora.

La célebre doctrina Carranza expresa que México tiene, por su posición geográfica, que ser - y en realidad lo es - el centinela avanzado del hispanismo de América. ¿Cuál será la opinión del actual gobierno mexicano respecto a la política que desarrollan los yankees en Centro América? ¿Acaso no habrán comprendido los gobiernos de Iberoamérica que los yankees se burlan de su prudente política adoptada en casos como el de Nicaragua? Es verdad que, por el momento, el Brasil, Venezuela y el Perú no tienen problemas de intervención, tal como lo manifestaron en la discusión del derecho de intervención en la Conferencia Panamericana celebrada en $\mathrm{La}$ Habana, en el año actual, por medio de sus representantes; pero si esos gobiernos tuvieran más conciencia de su responsabilidad histórica no esperarían que la conquista hiciera sus estragos en su propio suelo, y acudirían a la defensa de un pueblo hermano que lucha con el valor y la tenacidad que da la desesperación contra un enemigo criminal cien veces mayor y armado de todos los elementos modernos. Los gobiernos que se expresan en horas tan trágicas y culminantes de la historia en los términos en que lo hicieron Brasil, Venezuela, Perú y Cuba, ¿podrán tener mañana autoridad moral suficiente sobre los demás pueblos hermanos? ¿Tendrán derecho a ser oídos? 
Hoy es con los pueblos de la América Hispana con quienes hablo. Cuando un gobierno no corresponde a las aspiraciones de sus connacionales, éstos, que le dieron el poder, tienen el derecho de hacerse representar por hombres viriles y con ideas de efectiva democracia, y no por mandones inútiles, faltos de valor moral y de patriotismo, que avergüenzan el orgullo de una raza.

Somos noventa millones de hispanoamericanos y sólo debemos pensar en nuestra unificación, y comprender que el imperialismo yankee es el más brutal enemigo que nos amenaza y el único que está propuesto a terminar, por medio de la conquista, con nuestro honor racial y con la libertad de nuestros pueblos.

Los tiranos no representan a las naciones y a la libertad no se la conquista con flores.

Por eso es que, para formar un Frente Único y contener el avance del conquistador sobre nuestras patrias, debemos principiar por darnos a respetar en nuestra propia casa, y no permitir que déspotas sanguinarios como Juan Vicente Gómez y degenerados como Leguía, Machado y otros, nos ridiculicen ante el mundo como lo hicieron en la pantomima de La Habana.

Los hombres dignos de la América Latina debemos imitar a Bolívar, Hidalgo, San Martín; y a los niños mexicanos que el 13 de septiembre de 1847 cayeron acribillados por las balas yankees en Chapultepec, y sucumbieron en defensa de la Patria y de la Raza, antes que aceptar sumisos una vida llena de oprobio y de vergüenza, en que nos quiere sumir el imperialismo yankee.

Patria y Libertad.

$* * *$

\section{Plan de realización del supremo sueño de Bolívar}

Proyecto Original que el Ejército Defensor de la Soberanía Nacional de Nicaragua presenta a los representantes de los Gobiernos de los veintiún Estados Latinoamericanos.

\section{Exordio}

Variadas y diversas son las teorías concebidas para lograr, ya sea un acercamiento, ya una Alianza, o ya una Federación, que, comprendiendo a las veintiún fracciones de nuestra América, integren una sola Nacionalidad. Pero nunca como hoy se había hecho tan imperativa y necesaria esa unificación, unánimemente anhelada por el pueblo latinoamericano, ni se habían presentado las urgencias, tanto como las facilidades que actualmente existen para tan alto fin, históricamente prescrito, como obra máxima a realizar por los ciudadanos de la América Latina.

Ya hemos tenido oportunidad de declarar que se "cometió el primer error en nuestra América Indo-Latina al no haberla consultado para la apertura del Canal de Panamá; pero todavía podemos evitar un error más con el Canal de Nicaragua".

Hondamente convencidos, como estamos, de que el capitalismo norteamericano ha llegado a la última etapa de su desarrollo, transformándose, como consecuencia, en imperialismo; y que ya no atiende a teorías de derecho y de justicia, pasando sin respeto alguno por sobre los inconmovibles principios de independencia de las 
fracciones de la Nacionalidad Latinoamericana, consideramos indispensable, más aún, inaplazable, la Alianza de nuestros Estados Latinoamericanos para mantener incólume esa independencia, frente a las pretensiones del imperialismo de los Estados Unidos de Norte América, o frente al de cualquiera otra potencia a cuyos intereses se nos pretenda someter.

Antes de entrar en materia, deseo que se me permita bosquejar, aquí mismo, en qué circunstancias, cómo y por qué concebimos la idea de la necesidad intransferible de efectuar una Alianza entre nuestros Estados Latinoamericanos, que proponemos en el presente Proyecto.

Las condiciones en que ha venido realizándose nuestra lucha armada en Nicaragua contra las fuerzas invasoras norteamericanas y las de sus aliados, nos dieron el convencimiento de que nuestra persistente resistencia, larga, de tres años, podría prolongarse por dos, tres, cuatro, o quién sabe cuántos más; pero que al fin de la jornada, el enemigo, poseedor de todos los elementos y de todos los recursos, habría de anotarse el triunfo, supuesto que en nuestra acción nos hallábamos solos, sin contar con la cooperación imprescindible, oficial o extraoficial, de ningún Gobierno de nuestra América Latina, o la de cualquier otro país. Y fue esa visión sombría del porvenir, la que nos impelió a idear la forma mejor de evitar que el enemigo pudiera señalarse la victoria. Nuestro pensamiento trabajaba con la insistencia de un reloj, elaborando el panorama optimista de nuestra América triunfadora en el mañana.

Estábamos igualmente compenetrados de que el gobierno de los Estados Unidos de Norte América no abandonaría jamás sus impulsos para. atropellando la soberanía centroamericana, poder realizar sus ambiciosos proyectos en esa porción de nuestra América; proyectos de los que, en gran parte, depende el mantenimiento futuro del poderío norteamericano, aunque para ello tenga que pasar destruyendo una civilización y sacrificando innumerables vidas humanas.

De otro lado, Centro América aislada, menos aún, Nicaragua abandonada, contando sólo con la angustia y el dolor solidarios del pueblo latinoamericano, podrían evitar el que la voracidad imperialista construya el Canal Interoceánico y establezca la Base Naval proyectados, desgarrando tierras centroamericanas. Al propio tiempo, teníamos la clara visión de que el silencio con que los Gobiernos de la América Latina contemplaban la tragedia centroamericana, implicaba su aprobación tácita de la actitud, agresiva e insolente, asumida por los Estados Unidos de Norte América, en contra de una vasta porción de este Continente; agresión que significa, a la vez, la merma colectiva del derecho a la propia determinación de los Estados Latinoamericanos.

Obrando bajo el influjo de estas consideraciones, llegamos a comprender la necesidad absoluta de que el intenso drama vivido por las madres, esposas y huérfanos centroamericanos, despojados de sus seres más queridos en los campos de batalla de las Segovias por los soldados del imperialismo norteamericano, no fuera estéril, tampoco defraudada, antes bien, se aprovechará para el afianzamiento de la Nacionalidad Latinoamericana, rechazando cuantos tratados, pactos o convenios se hayan celebrado con pretensiones de legalidad que lesionen, en una u otra forma, la soberanía absoluta, tanto de Nicaragua, como de los demás Estados Latinoamericanos. Para lograrlo, nada más lógico, nada más decisivo ni vital, que la fusión de los veintiún Estados de nuestra América en una sola y única Nacionalidad Latinoamericana, de modo de poder considerar, dentro de ella, como consecuencia inmediata, los 
derechos sobre la ruta del Canal Interoceánico por territorio centroamericano y sobre el Golfo de Fonseca, en aguas también centroamericanas, así como todas aquellas otras zonas encerradas en la vasta extensión territorial que limitan el Río Bravo al Norte y el Estrecho de Magallanes al Sur, comprendidas las islas de estirpe latinoamericana, posibles de ser utilizadas, ya como puntos estratégicos, ya como vías de comunicación de interés común para la generalidad de los Estados Latinoamericanos. Empero, unidos a otros graves problemas que afectan la estabilidad autónoma de los Estados Latinoamericanos, lo que nos interesa salvar, sin más dilaciones, son la Base Naval en el Golfo de Fonseca y la ruta del Canal Interoceánico a través de Nicaragua; lugares que, en un día no remoto, llegarán a constituir tanto el imán como la llave del mundo y, por consiguiente, de hallarse bajo la soberanía latinoamericana, serán un baluarte para la defensa de su independencia sin limitaciones, y una válvula maravillosa para el desarrollo de su progreso material y espiritual rotundos.

Por ello, el Proyecto de que conocerá esta Magna Asamblea, afronta la solución de los problemas planteados en los siguientes Puntos Básicos.

Proyecto

1. La Conferencia de Representantes de los veintiún Estados integrantes de la $\mathrm{Na}$ cionalidad Latinoamericana, declara abolida la doctrina Monroe y, de consiguiente, anula el vigor que dicha doctrina pretende poseer para inmiscuirse en la política interna y externa de los Estados Latinoamericanos.

2. La Conferencia de Representantes de los veintiún Estados integrantes de la Nacionalidad Latinoamericana, declara expresamente reconocido el derecho de Alianza que asiste a los veintiún Estados de la América Latina Continental e Insular, y, por ende, establecida una sola Nacionalidad, denominada Nacionalidad Latinoamericana, haciéndose de ese modo efectiva la Ciudadanía Latinoamericana.

3. La Conferencia de Representantes de los veintiún Estados integrantes de la Nacionalidad Latinoamericana, declara acordar el establecimiento de Conferencias periódicas de Representantes exclusivos de los veintiún Estados de la Nacionalidad Latinoamericana, sin tener injerencia de ningún género en ellas, otra u otras nacionalidades.

4. La Conferencia de Representantes de los veintiún Estados integrantes de la Nacionalidad Latinoamericana, declara constituida la Corte de Justicia Latinoamericana, organismo que resolverá, en última instancia, sobre todos los problemas que afecten o puedan afectar en cualquier forma a los Estados Latinoamericanos y en los que la denominada Doctrina Monroe ha pretendido ejercer su influencia.

5. La Conferencia de Representantes de los veintiún Estados integrantes de la Nacionalidad Latinoamericana, resuelve que la Corte de Justicia Latinoamericana tenga como sede el territorio centroamericano comprendido entre la ruta canalera interoceánica a través de Nicaragua y la Base Naval que pueda establecerse en el Golfo de Fonseca, sin implicar esto un privilegio especial para los Estados Centroamericanos, ya que al señalar tal región de nuestra América como asiento de la Corte de Justicia Latinoamericana se persigue demostrar ante el mundo la vigilancia ejercida por los veintiún Estados Latinoamericanos, en conjunto, sobre aquella porción geográfica, que en este caso es, como ninguna otra porción, punto estratégico para la defensa de la Soberanía integral de la Nacionalidad Latinoamericana. 
6. La Conferencia de Representantes de los veintiún Estados integrantes de la Nacionalidad Latinoamericana, declara reconocer como Suprema y Única autoridad arbitral, a la Corte de Justicia Latinoamericana, en los casos de reclamaciones, litigios de límites y toda otra causa que, en una u otra forma, afecte o pueda afectar la estrecha y sólida armonía que debe normar las relaciones de los veintiún Estados Latinoamericanos.

7. La Conferencia de Representantes de los veintiún Estados integrantes de la Nacionalidad Latinoamericana, acuerda proceder a la inmediata organización de un Ejército compuesto por cinco mil doscientos cincuenta ciudadanos pertenecientes a la clase estudiantil, entre los dieciocho y los veinticinco años de edad, contando con profesores de Derecho y Ciencias Sociales. Estos profesores, así como la totalidad de los componentes del citado Ejército, deberán ser físicamente aptos para el servicio militar. Requisito indispensable para poder pertenecer al Ejército propuesto es el de poseer la Ciudadanía Latinoamericana.

Este Ejército no constituye el efectivo de las Fuerzas de Mar y Tierra de la Alianza Latinoamericana, sino que la Base fundamental de los efectivos con que habrá de contar la Nacionalidad Latinoamericana para la defensa y sostenimiento de su Soberanía.

La Base del efectivo de las Fuerzas de Mar y Tierra de la Alianza Latinoamericana constituye, al propio tiempo, una Representación simbólica del acuerdo existente entre los veintiún Estados Latinoamericanos, así como de su decisión por cooperar conjuntamente a la defensa de los intereses de la propia Nacionalidad latinoamericana.

8. La Conferencia de Representantes de los veintiún Estados integrantes de la Nacionalidad Latinoamericana, acuerda que cada uno de los veintiún Estados ante ella acreditados, proporcione doscientos cincuenta ciudadanos para la constitución del aludido Ejército.

9. La Conferencia de Representantes de los veintiún Estados integrantes de la Nacionalidad Latinoamericana, acuerda que cada uno de sus Gobiernos mandantes aporte de sus Tesoros Públicos una cantidad fija y proporcional para el sostenimiento de la Base del efectivo de las Fuerzas de Mar y Tierra de la Alianza Latinoamericana.

10. La Conferencia de Representantes de los veintiún Estados integrantes de la Nacionalidad Latinoamericana, acuerda investir al Ciudadano Presidente de la Corte de Justicia Latinoamericana con el carácter de Comandante en Jefe de las Fuerzas de Mar y Tierra de la Alianza Latinoamericana.

11. La Conferencia de Representantes de los veintiún Estados integrantes de la Nacionalidad Latinoamericana, aprueba que el período de duración de las funciones del Ciudadano Presidente de la Corte de Justicia Latinoamericana, así como el Comandante en Jefe de las Fuerzas de Mar y Tierra de la Alianza Latinoamericana, sea de seis años, en la inteligencia de que por acuerdo expreso de los Representantes de los veintiún Estados Latinoamericanos ante la Corte de Justicia Latinoamericana, su mandato podrá ser revocado, en caso de constituir su permanencia en tan alto cargo una amenaza para la buena marcha de las funciones que se tiene encomendado ese Tribunal Máximo.

12. La Conferencia de Representantes de los veintiún Estados integrantes de la Nacionalidad Latinoamericana, acuerda que la elección de Presidente de la Corte 
de Justicia Latinoamericana, se efectúe en el orden siguiente: Argentina, Bolivia, Brasil, Colombia, Costa Rica, Cuba, Chile, Ecuador, El Salvador, Guatemala, Honduras, Haití, México, Nicaragua, Paraguay, Perú, Panamá, Puerto Rico, República Dominicana, Uruguay y Venezuela.

13. La Conferencia de Representantes de los veintiún Estados integrantes de la Nacionalidad Latinoamericana, estatuye que la elección de Presidente de la Corte de Justicia Latinoamericana, Comandante en Jefe nato de las Fuerzas de Mar y Tierra de la Alianza Latinoamericana, será efectuada exclusivamente por los ciudadanos del Estado al cual corresponda designar el Funcionario aludido, en consideración a que son los ciudadanos Latinoamericanos de cada Estado, quienes se hallan más capacitados para conocer de las virtudes públicas y privadas del ciudadano a quien les toque elegir para tan alto cargo.

14. La Conferencia de Representantes de los veintiún Estados integrantes de la Nacionalidad Latinoamericana, inviste a los Representantes de los Gobiernos de los veintiún Estados Latinoamericanos ante la Corte de Justicia Latinoamericana, del derecho de veto en caso de que la aceptación en el seno de este Alto Tribunal del Presidente electo, implicara algún daño o perjuicio para la mejor realización de sus fines.

15. La Conferencia de Representantes de los veintiún Estados integrantes de la Nacionalidad Latinoamericana, acuerda que la elección de los doscientos cincuenta ciudadanos que habrán de representar a cada uno de dichos Estados en el seno de las Fuerzas de Mar y Tierra de la Alianza Latinoamericana, se efectúe mediante la realización de concursos especiales convocados para el efecto por los Gobiernos de los veintiún Estados Latinoamericanos. Los doscientos cincuenta estudiantes que en cada Estado resulten vencedores en los concursos, comprobando así sus aptitudes físicas e intelectuales, serán los que cada uno de los veintiún Estados envíe como auténticos Representantes suyos ante las Fuerzas de Mar y Tierra de la Alianza Latinoamericana.

16. La Conferencia de Representantes de los veintiún Estados integrantes de la Nacionalidad Latinoamericana, acuerda que cada uno de los Gobiernos mandantes, nombre un número determinado de profesores de Derecho y Ciencias Sociales, para ejercer sus funciones de tales, de conformidad con el punto básico 7.

Los doscientos cincuenta ciudadanos vencedores en los concursos de cada Estado, serán quienes elijan, de entre los componentes del Cuerpo de Profesores de su propio Estado, a aquél que habrá de representar a éste en el seno de la Corte de Justicia Latinoamericana.

17. La Conferencia de Representantes de los veintiún Estados integrantes de la Nacionalidad Latinoamericana, declara que una de las obligaciones fundamentales, tanto de los componentes de la Corte de Justicia Latinoamericana como de los miembros de las Fuerzas de Mar y Tierra de la Alianza Latinoamericana, es la de rendir un informe detallado de sus actividades durante el período de su gestión, ante las Conferencias de Representantes de los veintiún Estados Latinoamericanos, que esta propia Conferencia ha acordado deben realizarse periódica e intransferiblemente.

18. La Conferencia de Representantes de los veintiún Estados integrantes de la Nacionalidad Latinoamericana, acuerda que tanto los componentes de la Corte de Justicia Latinoamericana como los de las Fuerzas de Mar y Tierra de la Alianza 
Latinoamericana, protestarán, ante la Conferencia de Representantes de los veintiún Estados Latinoamericanos, fidelidad a los Principios constitutivos de la Nacionalidad Latinoamericana y a la Ley Orgánica y Reglamentos estatuidos para su funcionamiento, comprometiéndose a velar y hacer velar con lealtad absoluta por la conservación de la Soberanía e Independencia inalienables de la Nacionalidad Latinoamericana, cuya confianza les ha sido depositada.

19. La Conferencia de Representantes de los veintiún Estados integrantes de la Nacionalidad Latinoamericana, acuerda que los Grados y Títulos otorgados por las Fuerzas de Mar y Tierra de la Alianza Latinoamericana a sus componentes, serán reconocidos en todos y cada uno de los Estados Latinoamericanos, en la plenitud de su validez.

20. La Conferencia de Representantes de los veintiún Estados integrantes de la Nacionalidad Latinoamericana, acuerda que cada uno de los Gobiernos de los respectivos Estados, ante ella acreditados, acepta la permanencia de un miembro de las Fuerzas de Mar y Tierra de la Alianza Latinoamericana, en sus Estados Mayores, patentizando así, con una prueba más, la vinculación existente entre cada uno de los Gobiernos de los veintiún Estados Latinoamericanos y las Fuerzas de Mar y Tierra de la Alianza Latinoamericana.

21. La Conferencia de Representantes de los veintiún Estados integrantes de la Nacionalidad Latinoamericana, prescribe que a todos los componentes de las Fuerzas de Mar y Tierra de la Alianza Latinoamericana les está terminantemente prohibido, desde el día de su ingreso a dicho organismo, pertenecer a Partido Político alguno y desarrollar actividades de tal naturaleza, dentro o fuera de la Nacionalidad Latinoamericana.

22. La Conferencia de Representantes de los veintiún Estados integrantes de la Nacionalidad Latinoamericana, acuerda facultar al Presidente de la Corte de Justicia Latinoamericana y Comandante de las Fuerzas de Mar y Tierra de la Alianza Latinoamericana, para que pueda proponer a los Gobiernos de los veintiún Estados los diplomáticos, técnicos en política internacional y expertos, cuya capacidad haya sido prácticamente comprobada en los organismos antes señalados.

23. La Conferencia de Representantes de los veintiún Estados integrantes de la Nacionalidad Latinoamericana, designa una Comisión encargada de elaborar la Ley Orgánica y Reglamentos que habrán de regir el funcionamiento, tanto de la Corte de Justicia Latinoamericana como de las Fuerzas de Mar y Tierra de la Alianza Latinoamericana, poniéndolas en vigor, previa su aprobación por los representantes de los Gobiernos de los veintiún Estados Latinoamericanos.

24. La Conferencia de Representantes de los veintiún Estados integrantes de la Nacionalidad Latinoamericana, declara que la Corte de Justicia Latinoamericana, así como las Fuerzas de Mar y Tierra de la Alianza Latinoamericana, reconocen y se esforzarán por mantener la Soberanía absoluta de los veintiún Estados Latinoamericanos, y que las gestion.es que efectúen en uso de sus atribuciones no entrañan limitación a la Soberanía de ninguno de los Estados Latinoamericanos, ya que lo que pudiera considerarse como limitación a la expresada Soberanía absoluta, se hace de acuerdo con el Principio de Nacionalidad Latinoamericana, para formar la cual todos y cada uno de los Estados Latinoamericanos conceden a esta idea de defensa y bienestar comunes todo aquello que, sin lesionar en caso alguno las normas de la 
vida interior de cada Estado, tienda a robustecer y afianzar dicha Nacionalidad Latinoamericana.

25. La Conferencia de Representantes de los veintiún Estados integrantes de la Nacionalidad Latinoamericana, declara que, en caso de guerra civil suscitada en cualquiera de los Estados signatarios del Pacto de Alianza. corresponde el derecho a las partes beligerantes para solicitar, si lo creyeran conveniente, contingentes armados de las Fuerzas de Mar y Tierra de la Alianza Latinoamericana; contingentes que, dado su carácter neutral, constituirán una garantía efectiva para todo aquello que, siempre de existir una razón que lo justifique ante el concepto de la Corte de Justicia Latinoamericana, se desee poner fuera del dominio de las partes beligerantes.

26. La Conferencia de Representantes de los veintiún Estados integrantes de la Nacionalidad Latinoamericana, declara terminantemente que la única capacitada para realizar las obras de apertura del Canal y la construcción de una Base Naval en el Golfo de Fonseca, en territorio Centroamericano, así como toda otra obra que implique una utilidad común para los veintiún Estados Latinoamericanos, es la Nacionalidad Latinoamericana, en su provecho directo y sin comprometer en lo más mínimo la Soberanía plena de algún o algunos Estados signatarios del Pacto de Alianza.

27. La Conferencia de Representantes de los veintiún Estados integrantes de la Nacionalidad Latinoamericana, aclara que si el desarrollo material y los recursos económicos actuales no son, por el momento, suficientes para realizar la apertura de la vía de comunicación interoceánica por territorio Centroamericano y el establecimiento de una Base Naval en el Golfo de Fonseca, o en cualquier otro lugar estratégico para la defensa de la Soberanía e independencia de la Nacionalidad Latinoamericana, los Estados signatarios del Pacto de Alianza se reservarán la totalidad de los derechos para la construcción o establecimiento de las obras aludidas, comprometiéndose a que, en ningún caso, la Nacionalidad Latinoamericana permitirá la enajenación, venta, cesión o arrendamiento de las obras en cuestión, o de otras cualesquiera, que comprometan la estabilidad de la Soberanía e independencia Latinoamericanas, a potencia o potencias extrañas a la Nacionalidad Latinoamericana.

28. La Conferencia de Representantes de los veintiún Estados integrantes de la Nacionalidad Latinoamericana, acuerda que al Plan de realización del supremo sueño de Bolívar efectuarse cualquiera de las obras, ya sea el Canal Interoceánico, ya la Base Naval, la Nacionalidad Latinoamericana se compromete a exigir que la empresa o empresas encomendadas de dar realidad a tales obras, indemnicen a los ciudadanos de los Estados afectados si al efectuarse aquéllas, sufrieren éstos en sus vidas o intereses.

29. La Conferencia de Representantes de los veintiún Estados integrantes de la Nacionalidad Latinoamericana, acuerda que, en los casos de agresión por una o varias potencias contra uno o varios Estados de la Nacionalidad Latinoamericana, los Estados Latinoamericanos procederán unánimemente a expresar su protesta oficial contra la o las potencias agresoras, bajo la amenaza de que efectuarán el retiro inmediato y conjunto de sus Representantes Diplomáticos acreditados ante la o las potencias agresoras.

30. La Conferencia de Representantes de los veintiún Estados integrantes de la Nacionalidad Latinoamericana, aprueba que si después de producidas las 
representaciones de que habla el punto básico anterior, no se lograra la satisfacción exigida a la o las potencias agresoras, los Gobiernos de los veintiún Estados Latinoamericanos, procederán a la confiscación automática de los intereses e inversiones que la o las potencias agresoras tuvieren dentro de los límites de la Nacionalidad Latinoamericana, sosteniendo con el producto de tal expropiación la guerra a que diere lugar la agresión de la o las potencias extranjeras.

31. La Conferencia de Representantes de los veintiún Estados integrantes de la Nacionalidad Latinoamericana, declara que los Gobiernos de los veintiún Estados usarán para la defensa de la Soberanía Latinoamericana, en el caso de que un conflicto internacional no ameritase el rompimiento de las hostilidades, el boicot económico contra la o las potencias que originaran la fricción, cancelando tanto la adquisición como la venta de productos con la o las potencias que provocasen el empleo de esta medida.

32. La Conferencia de Representantes de los veintiún Estados integrantes de la Nacionalidad Latinoamericana, acuerda adoptar, como medida inmediata posterior a la firma del Pacto de Alianza, la Constitución de un Comité de Banqueros Latinoamericanos, oficialmente respaldado, que tenga por objeto elaborar y realizar el plan por medio del cual la Nacionalidad Latinoamericana logre, con fondos propios, cancelar los contratos que existan entre los Estados Latinoamericanos y los Estados Unidos de Norte América, haciéndose cargo dicho Comité de Banqueros de la construcción de obras materiales y vías de comunicación y transporte, así como de la flotación de empréstitos que, en virtud de los tratados ya existentes entre los Estados Latinoamericanos y los Estados Unidos de Norte América, los Gobiernos de los primeros necesitasen.

33. La Conferencia de Representantes de los veintiún Estados integrantes de la Nacionalidad Latinoamericana, acuerda que la Nacionalidad Latinoamericana use de todos los medios diplomáticos y pacíficos que las circunstancias aconsejen, a fin de adquirir por intermedio del Comité de Banqueros Latinoamericanos, los derechos que pretenden mantener los Estados Unidos de Norte América sobre el Canal de Panamá, quedando éste, como consecuencia, bajo el dominio de la Soberanía Absoluta de la Nacionalidad Latinoamericana.

34. La Conferencia de Representantes de los veintiún Estados integrantes de la Nacionalidad Latinoamericana, encomienda a la Corte de Justicia Latinoamericana, la misión de realizar una investigación minuciosa en los Estados de Puerto Rico. Cuba, República Dominicana, Haití, Panamá, México, Honduras y Nicaragua, acerca de las pérdidas de vidas e intereses sufridos por los ciudadanos latinoamericanos en los mencionados Estados, durante las ocupaciones e invasiones ordenadas por diversos Gobiernos de los Estados Unidos de Norte América.

35. La Conferencia de Representantes de los veintiún Estados integrantes de la Nacionalidad Latinoamericana, resuelve que, de acuerdo con el informe que rinda la Corte de Justicia Latinoamericana, la Nacionalidad Latinoamericana proceda a exigir la desocupación inmediata y total de los Estados que se hallen intervenidos, recuperándose automáticamente las porciones territoriales empleadas por los Estados Unidos de Norte América como Bases Navales, centros de aprovisionamientos, o en otras obras utilizadas para posibles agresiones y que entrañen menoscabo de la Soberanía de los Estados Latinoamericanos. 
36. La Conferencia de Representantes de los veintiún Estados integrantes de la Nacionalidad Latinoamericana, declara que, ni la Corte de Justicia Latinoamericana, ni ningún Estado en particular, tomarán en consideración. al realizar la investigación antes dicha, la pretendida responsabilidad contraída por los Estados Latinoamericanos con el Gobierno de los Estados Unidos de Norte América, al defender aquéllos, en el curso o durante las ocupaciones e invasiones efectuadas por las tropas de los Estados Unidos de Norte América, sus soberanías atropelladas, ya que las pérdidas de vidas e intereses norteamericanos, como consecuencia de tales agresiones, constituyen simplemente resultantes del ejercicio del derecho de defensa, inherente a todo pueblo agredido.

37. La Conferencia de Representantes de los veintiún Estados integrantes de la Nacionalidad Latinoamericana, acuerda adoptar las medidas conducentes a que el ingreso de ciudadanos de los Estados Unidos de Norte América en territorio latinoamericano, no entrañe, por ningún motivo, una amenaza a los intereses de cualquier género de la Nacionalidad Latinoamericana, evitando, así mismo, que el capital financiero norteamericano penetre en los Estados Latinoamericanos en forma de inversiones, o en otras formas distintas, liquidando, de este modo, el empleo por el Gobierno yanqui del socorrido recurso de "proteger las vidas e intereses de norteamericanos" para violar la Soberanía de los Estados Latinoamericanos.

38. La Conferencia de Representantes de los veintiún Estados integrantes de la Nacionalidad Latinoamericana, acuerda realizar la unificación de las Tarifas aduanales de los veintiún Estados, efectuando, además, sobre el arancel ya unificado, un descuento del $25 \%$ para las exportaciones o importaciones de los productos de los veintiún Estados en los mercados de la Nacionalidad Latinoamericana. Las expresiones de cultura, libros, revistas, cuadros y demás obras necesarias para el desarrollo de las ciencias y artes, gozarán de la más absoluta franquicia en los veintiún Estados Latinoamericanos.

39. La Conferencia de Representantes de los veintiún Estados integrantes de la Nacionalidad Latinoamericana, acuerda que los Gobiernos, en ella acreditados, efectúen un intercambio metódico de estudiantes de Ciencias Económicas y Sociales de los veintiún Estados Latinoamericanos, de modo que cada uno de éstos cree las becas correspondientes a determinado número de estudiantes por cada Estado.

40. La Conferencia de Representantes de los veintiún Estados integrantes de la Nacionalidad Latinoamericana, acuerda que los Gobiernos ante ella acreditados fomenten de manera especial el turismo latinoamericano, de manera de promover el acercamiento y mutuo conocimiento entre los ciudadanos de los veintiún Estados Latinoamericanos, concediéndoseles a los turistas, entre otras ventajas, una rebaja del $10 \%$ en los ferrocarriles, vapores, aviones y demás medios de comunicación y transporte que existan o se establezcan en los veintiún Estados de nuestra América.

41. La Conferencia de Representantes de los veintiún Estados integrantes de la Nacionalidad Latinoamericana, acuerda nombrar una Comisión especial con el fin de que ésta elabore las Bases y convoque los concursos a que hubiere lugar, para dar oportunidad así a que los intelectuales y cientistas latinoamericanos sean quienes presenten las fórmulas sobre las cuales deberá constituirse el Comité de Banqueros Latinoamericanos; la manera mejor de promover el mutuo conocimiento entre los veintiún Estados Latinoamericanos, el modo de reincorporar el Canal de Panamá a 
la Nacionalidad Latinoamericana; y, en general, elaborar las Bases especiales sobre cada una de las iniciativas encerradas en este Proyecto y que las necesiten.

42. La Conferencia de Representantes de los veintiún Estados integrantes de Ja Nacionalidad Latinoamericana, proclama reconocer bajo la denominación de Bandera de la Nacionalidad Latinoamericana, la que en esta misma Conferencia tiene la honra de presentar el Ejército Defensor de la Soberanía Nacional de Nicaragua. Ella expresa, en un armonioso conjunto de colores, el símbolo de la fusión de cada una de las enseñas de los veintiún Estados Latinoamericanos, hoy congregados en una sola, fuerte y gloriosa Nacionalidad.

43. La Conferencia de Representantes de los veintiún Estados integrantes de la Nacionalidad Latinoamericana, adopta como lema oficial de la Alianza Latinoamericana, encarnada en la Corte de Justicia Latinoamericana y en las Fuerzas de Mar y Tierra de la Alianza Latinoamericana, aquel que, interpretando el fecundo destino de la Nacionalidad, que insurge en la historia del mundo marcando nuevos derroteros, adoptara la vibrante nueva generación mexicana, como lema de sus hondas inquietudes creadoras: "Por mi raza hablará el espiritu".

44. La Conferencia de Representantes de los veintiún Estados integrantes de la Nacionalidad Latinoamericana, que reúne en fraternal acercamiento a los Gobiernos y pueblos de los veintiún Estados, aclama como denominación del lugar en que habrá de tener su Sede la Corte de Justicia Latinoamericana, la de Simón Bolívar, elevando, así mismo, como un homenaje de admiración al recuerdo de este egregio realizador de la Independencia Latinoamericana, en el Salón de Honor de la Corte de Justicia Latinoamericana, un monumento coronado por la prócer figura del máximo forjador de pueblos libres.

\section{Conclusión}

Ciudadanos Representantes de los veintiún Estados Latinoamericanos:

Al dejar expuesto el Proyecto original que el Ejército Defensor de la Soberanía Nacional de Nicaragua presenta ante esta Magna Asamblea con el alto propósito de realizar la Alianza de inaplazables urgencias entre los veintiún Estados dispersos de la Nacionalidad Latinoamericana, nos hallamos plenamente conscientes de la enorme responsabilidad histórica que contraemos con nuestra América y con el Mundo. Por ello, no hemos intentado la exposición de un plan fantasioso y aventurado, sino que, interpretando nuestra realidad, nos hemos esforzado por hacer de este Proyecto algo efectivo y capaz de afrontar la solución de nuestros problemas más inmediatos, afrontando, antes que nada, la necesidad imperativa de realizar la unánimemente ansiada Alianza Latinoamericana, a la que sólo pueden oponerse teorías de un lamentable escepticismo y de escaso alcance en la política interna y exterior de nuestros Estados.

Afirmados en la realidad, proponemos una Alianza y no una Confederación de los veintiún Estados de nuestra América. Comprendemos que para llegar a este gran fin precisa, primero que nada, la fundamentación de una base elemental que la Alianza nos la presta. Esta no es, pues, la culminación de nuestras aspiraciones. Constituye únicamente el primer paso en firme para otros venideros y fecundos esfuerzos de nuestra Nacionalidad. 
Quizá los hombres poseedores de ideas avanzadas y universalistas, pensarán en que nuestros anhelos encontraron fronteras en la extensión geográfica limitada por el Río Bravo al Norte y el Estrecho de Magallanes en el Sur de nuestra América. Pero mediten ellos en la necesidad vital que tiene nuestra América Latina de realizar una Alianza, previa a una Confederación de los veintiún Estados que la integran, asegurando de ese modo nuestra libertad y nuestra Soberanía interiores, amenazadas por el más voraz de los imperialismos, para cumplir seguidamente con el gran destino de la Nacionalidad Latinoamericana ya culminada, como tierra de promisión para los hombres de todos los pueblos y de todas las razas.

Patria y Libertad. 